\title{
Superação da dormência em sementes de crista de galo
}

\author{
Overcoming of dormancy of crista de galo in seeds
}

\begin{abstract}
Elane Grazielle Borba de Sousa Ferreira ${ }^{\mathrm{I}^{*}}$ Valderez Pontes Matos $^{\mathrm{II}}$ Lúcia Helena de Moura Sena ${ }^{\mathrm{II}}$ Anna Gorett de Figueiredo Almeida Sales ${ }^{\mathrm{I}}$ Helder Henrique Duarte Santos ${ }^{\mathrm{II}}$
\end{abstract}

\section{RESUMO}

O presente trabalho teve como objetivo avaliar o efeito de diferentes tratamentos pré-germinativos na superação da dormência de sementes de Celosia cristata L., que foram submetidas aos seguintes tratamentos: choque térmico exposição em estufa $a 0^{\circ} \mathrm{C}$ por 5 minutos, escarificação química com ácido sulfúrico por um minuto, 30 segundos e 5 minutos, imersão das sementes intactas em água a $80^{\circ} \mathrm{C}$ até resfriamento, imersão das sementes intactas em água à temperatura ambiente por 24 horas e a testemunha - sem tratamento. $\mathrm{Na}$ avaliação do efeito dos tratamentos, foram determinados a porcentagem final, primeira contagem $e$ índice de velocidade de germinação, como também o comprimento da raiz e do hipocótilo. As sementes de C. cristata L. quando oriundas de frutos maduros não necessitam da utilização de tratamentos para superação da dormência.

Palavras-chave: Celosia cristata, germinação, vigor.

\section{ABSTRACT}

This study had the objective of evaluating the effect of different pre-germination treatments for overcome of dormancy of Celosia cristata seeds, subjected to the following treatments: heat shock - exhibition in an oven at $80^{\circ} \mathrm{C}$ for 5 minutes, chemical scarification with sulfuric acid for 1 minute, 30 seconds and 5 minutes, immersion of intact seeds in water the $80^{\circ} \mathrm{C}$ at cooling and immersion of intact seeds in water for 24 hours, and the control - no treatment. We evaluated the following final percentage, first count and germination speed index, but also the length of the primary root and hypocotyl. The seeds of $\boldsymbol{C}$. cristata when coming from ripe fruits do not require the use of treatments to overcoming dormancy.

Key words: Celosia cristata, germination, vigor.

\section{INTRODUÇÃO}

A Celosia cristata L. é conhecida popularmente como crista de galo ou crista celosia, pertence à família Amaranthaceae, originária da América Tropical (LORENZI \& SOUZA, 2008; GILMAN \& HOWE, 1999). De porte herbáceo, é utilizada também como hortaliça em muitos países africanos (OKUSANYA, 1980), cuja propagação é por sementes produzidas em grande quantidade e seu potencial ornamental se deve à inflorescência aveludada de diversas cores (LORENZI \& SOUZA, 2008).

Quando a propagação de espécies é feita por sementes, é importante conhecer os fatores que influenciam a sua porcentagem e velocidade de germinação, as quais podem ser extrínsecos, a exemplo da luz, temperatura e umidade, e intrínsecos, como morfologia, viabilidade e dormência (BIONDI \& LEAL, 2008).

A dormência de sementes pode ser definida como um fenômeno pelo qual sementes de uma determinada espécie, mesmo estando viáveis e mantidas em condições ambientais favoráveis, não germinam (DAVIDE \& SILVA, 2008). De acordo com MARCOS FILHO (2005), a dormência é um mecanismo de defesa das sementes contra variações do ambiente que dificultam ou impedem sua atividade metabólica normal durante determinado período, como também tem fundamental importância para a perpetuação e o

IPrograma de Pós-graduação em Ciências Florestais, Universidade Federal Rural de Pernambuco (UFRPE), 52171-900, Recife, PE, Brasil. E-mail: egbsf@bol.com.br. *Autor para correspondência.

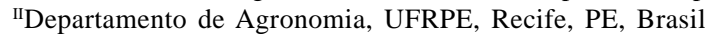


estabelecimento de muitas espécies vegetais nos mais variados ambientes (ZAIDAN \& BARBEDO, 2004).

Quando todas as condições necessárias à germinação são oferecidas à semente e mesmo assim ela não germina, há forte possibilidade de haver algum bloqueio que deve ser removido ou superado para que o processo da germinação ocorra (ZAIDAN \& BARBEDO, 2004). Devido a este fato, geralmente a dormência das sementes é uma característica indesejável na agricultura, uma vez que a rápida germinação e crescimento das plântulas são desejados (BEWLEY, 1997). Porém existe a necessidade de se utilizar métodos pré-germinativos que permitam superar a dormência, possibilitando a expressão da máxima germinação (JACOB JUNIOR et al., 2004) em menor espaço de tempo.

O fenômeno da dormência é comum em sementes de algumas hortaliças, forrageiras, frutíferas, espécies arbóreas e ornamentais, que não germinam logo após a colheita devido a mecanismos de bloqueio (DIAS, 2005). Nesse sentido, vários estudos comprovaram a existência de dormência em sementes de algumas espécies, para as quais há necessidade de tratamentos para sua superação, a exemplo das sementes de Adenanthera pavonina L., que devem ser imersas em ácido sulfúrico por 22 minutos ou serem submetidas à abrasão em lixa durante 20 segundos (RODRIGUES et al., 2009).

Com intuito de verificar se as sementes de Celosia cristata são dormentes, o presente trabalho teve como objetivo avaliar diferentes métodos para superação da dormência das sementes desta espécie, permitindo a máxima expressão do poder germinativo.

\section{MATERIAL E MÉTODOS}

As sementes de Celosia cristata foram submetidas aos seguintes tratamentos prégerminativos: choque térmico - exposição em estufa a $80^{\circ} \mathrm{C}$ por 5 minutos $\left(\mathrm{T}_{2}\right)$, escarificação química com ácido sulfúrico por 1 minuto $\left(\mathrm{T}_{3}\right), 30$ segundos $\left(\mathrm{T}_{4}\right)$ e 5 minutos $\left(\mathrm{T}_{5}\right)$, imersão das sementes intactas em água a $80^{\circ} \mathrm{C}$ até resfriamento $\left(\mathrm{T}_{6}\right)$, imersão das sementes intactas em água à temperatura ambiente por 24 horas $\left(\mathrm{T}_{7}\right)$ e a testemunha - sem tratamento $\left(\mathrm{T}_{1}\right)$. Após serem submetidas aos diferentes tratamentos, as sementes foram semeadas sobre substrato papel mata borrão, colocados em caixas plásticas transparentes com tampa, o qual foi umedecido com solução de nistatina a $0,2 \%$, na quantidade equivalente a 2,5 o peso da massa seca do substrato, sendo o teste de germinação conduzido em germinador tipo Biochemical Oxigen Demand (B.O.D.), regulado à temperatura constante de $25^{\circ} \mathrm{C}$ e sob luz contínua, adotando-se como critério o surgimento do hipocótilo e a consequente emergência dos cotilédones.

As variáveis avaliadas foram as seguintes: porcentagem final de germinação - correspondeu à porcentagem total de sementes germinadas até o 26음 dia após a semeadura; primeira contagem - referente à porcentagem de sementes germinadas no período de ocorrência das primeiras plântulas normais, que foi no quarto dia após a semeadura; índice de velocidade de germinação (IVG) - calculou-se pelo somatório do número de sementes germinadas a cada dia, dividido pelo número de dias decorridos entre a semeadura e a germinação, de acordo com a fórmula de MAGUIRE (1962); comprimento da raiz primária e do hipocótilo no final do teste de germinação, a raiz e o hipocótilo das plântulas normais de cada repetição foram medidos com régua graduada em centímetros e os resultados expressos em cm plântula ${ }^{-1}$.

O delineamento experimental utilizado foi o inteiramente ao acaso, em quatro repetições de 25 sementes, os dados foram submetidos à análise de variância e as médias comparadas pelo teste de Tukey, ao nível de 5\% de probabilidade, sendo os dados em porcentagem transformados em arc sen (n/100) 0,5. Para realização da análise, foi utilizado o software estatístico ESTAT, versão 2.0 (ESTAT, 1994) desenvolvido pela FCAV/UNESP.

\section{RESULTADOS E DISCUSSÃO}

As maiores porcentagens de germinação de sementes de $\boldsymbol{C}$. cristata L. foram obtidas nos tratamentos de escarificação química com ácido sulfúrico por 30 segundos $\left(\mathrm{T}_{4}\right)$ e imersão em água à temperatura ambiente por 24 horas $\left(\mathrm{T}_{7}\right)$, embora não tenham diferido estatisticamente das sementes da testemunha. Os tratamentos com choque térmico $\left(\mathrm{T}_{2}\right)$ e imersão em água a $80^{\circ} \mathrm{C}$ até resfriamento $\left(\mathrm{T}_{6}\right)$ ocasionaram as menores porcentagens de germinação, com um percentual entre 1 e $9 \%$, respectivamente (Figura 1).

Para as sementes de Stenolobium stans (Juss) Seem., constatou-se alta porcentagem de germinação sem a utilização de tratamento para superação da dormência (DAVIDE \& SILVA, 2008). Um dos tratamentos pré-germinativos indicados para superar a dormência de sementes de Piptadenia moniliformis Benth. foi o ácido sulfúrico (95\%) por 10 e 15 minutos (BENEDITO et al., 2008). De acordo com MELO \& RODOLFO JÚNIOR (2006), as sementes de Cassia grandis L.f., expostas à temperatura de $80^{\circ} \mathrm{C}$ por um, três e cinco minutos, não germinaram, enquanto 


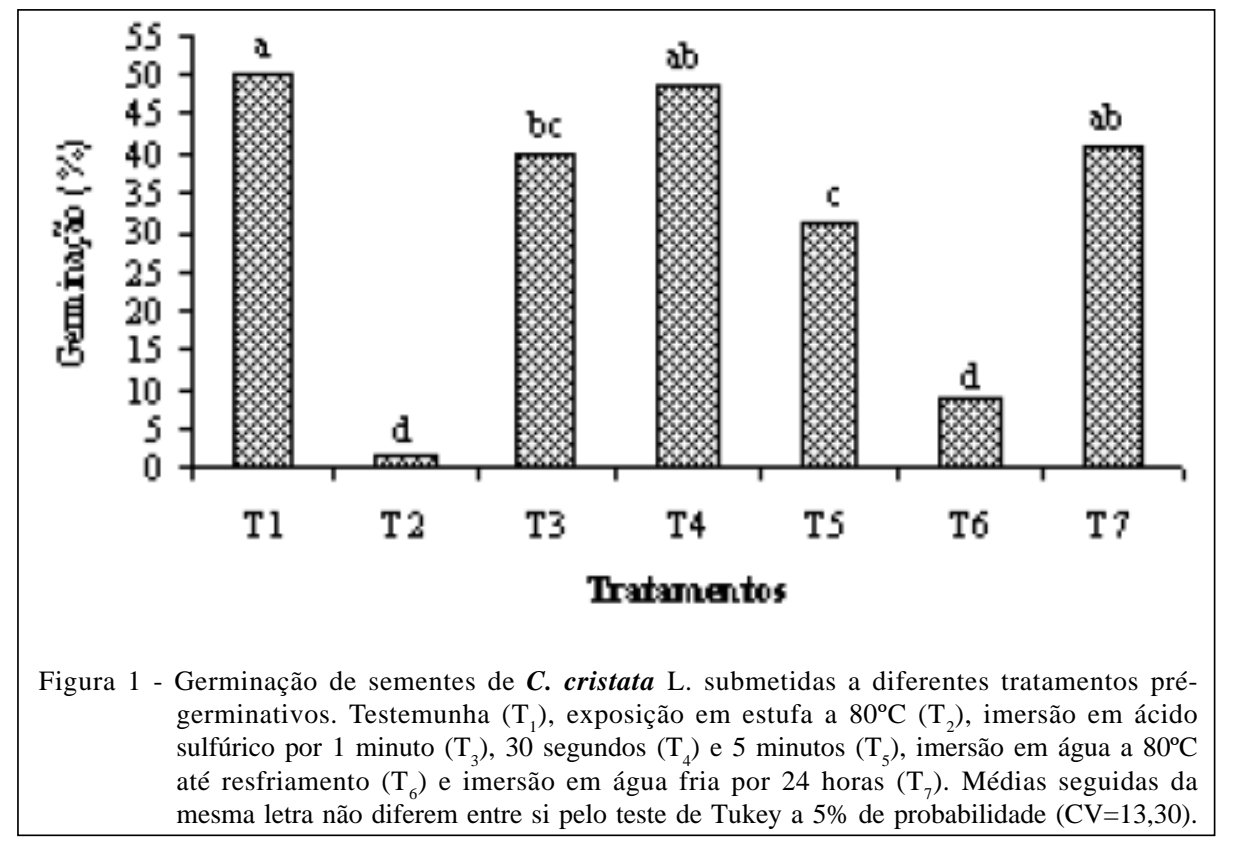

que as de Stylosanthes macrocephala e $\boldsymbol{S}$. capitata SW. submetidas a temperaturas elevadas propiciaram a superação da dormência, sendo o melhor tratamento a exposição à temperatura de 60 e $70^{\circ} \mathrm{C}$ por 15 horas, respectivamente, proporcionando maior porcentagem e velocidade de germinação (ALENCAR et al., 2009).

Os tratamentos com ácido sulfúrico por 30 segundos $\left(\mathrm{T}_{4}\right)$ e imersão em água por 24 horas $\left(\mathrm{T}_{7}\right)$ proporcionaram maior porcentagem de germinação das sementes de $\boldsymbol{C}$. cristata L. na primeira contagem (Figura 2), em relação aos demais tratamentos, exceto em relação à testemunha. Porém a porcentagem foi drasticamente reduzida quando foram utilizados os tratamentos choque térmico e imersão em água a $80^{\circ} \mathrm{C}$ até resfriamento para superação da dormência das sementes, provavelmente devido à temperatura alta

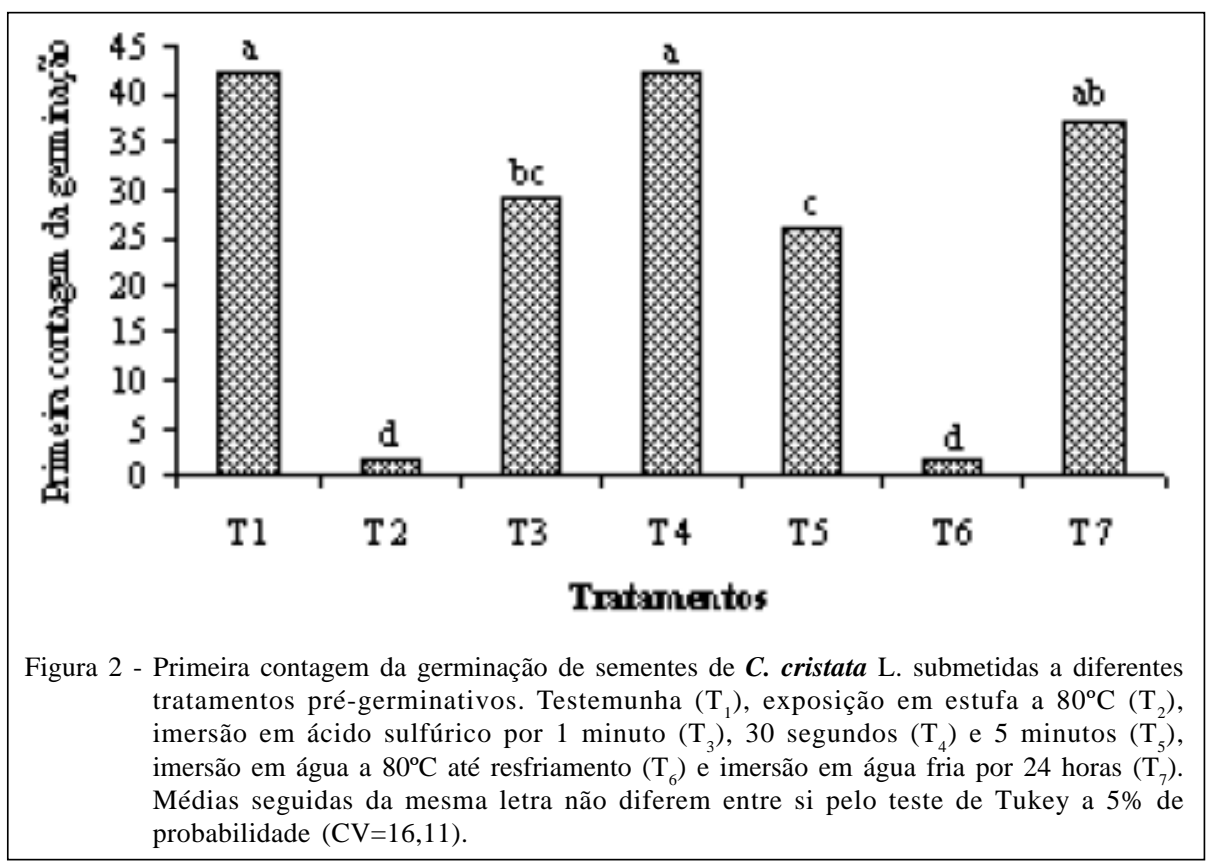

Ciência Rural, v.42, n.5, mai, 2012. 
que, consequentemente, pode ter causado a morte do embrião. Tais resultados são semelhantes aos do trabalho realizado com a espécie Ipomoea quamoclit, em que as sementes, ao serem mantidas em água quente $\left(98^{\circ} \mathrm{C}\right)$, perderam a viabilidade (AZANIA et al., 2009).

A maior rapidez na germinação das sementes de $\boldsymbol{C}$. cristata foi quando foram semeadas sem nenhum tratamento pré-germinativo, com escarificação química em ácido sulfúrico por 30 segundos $\left(\mathrm{T}_{4}\right)$ e imersão em água por 24 horas $\left(\mathrm{T}_{7}\right)$, enquanto que a germinação ocorreu de forma muito lenta e desuniforme quando elas ficaram expostas em estufa a $80^{\circ} \mathrm{C}$ por 5 minutos $\left(\mathrm{T}_{2}\right)$ e imersão em água a $80^{\circ} \mathrm{C}$ até resfriamento $\left(\mathrm{T}_{6}\right)$ (Figura 3). A imersão em água a $80^{\circ} \mathrm{C}$, que ocasionou menor velocidade de germinação nas sementes de $\boldsymbol{C}$. cristata L., foi um dos tratamentos que proporcionou maior porcentagem e velocidade de germinação às sementes de Ochroma lagopus Sw. (BARBOSA et al., 2004). Para sementes de Schinopsis brasiliense Engl., a escarificação química com ácido sulfúrico por três minutos ocasionou menor velocidade de germinação (ALVES et al., 2007).

Quanto ao comprimento da raiz e do hipocótilo de plântulas de $\boldsymbol{C}$. cristata L. (Figura 4), os melhores resultados foram obtidos com os tratamentos de escarificação química com ácido sulfúrico $\left(\mathrm{H}_{2} \mathrm{SO}_{4}\right)$ por 1 minuto, 30 segundos e imersão em água por 24 horas, porém não houve diferença significativa dos resultados com os da testemunha (sem nenhum tratamento).
Os tratamentos de imersão em ácido sulfúrico por 5, 15, 30, 45 e 60 minutos foram os que proporcionaram maior crescimento da parte aérea das plântulas de Parkia platycephala Benth. (NASCIMENTO et al., 2009). No entanto, para Apeiba tibourbou Aubl., as sementes submetidas à imersão em ácido sulfúrico por 10 minutos e as intactas (testemunha) originaram plântulas menos vigorosas (PACHECO \& MATOS, 2009).

Apesar da escarificação química com ácido sulfúrico por 30 segundos e embebição em água por 24 horas terem favorecido a germinação e elevado o nível de vigor em relação aos demais tratamentos prégerminativos, para todas as características avaliadas, a testemunha não foi significativamente inferior a nenhum dos tratamentos utilizados, o que determina que as sementes de $\boldsymbol{C}$. cristata L., quando oriundas de frutos maduros, não necessitam da utilização de tratamentos para superação da dormência.

Os tratamentos de exposição das sementes a $80^{\circ} \mathrm{C}$ em estufa por 5 minutos, imersão em água a $80^{\circ} \mathrm{C}$ até resfriamento e escarificação química com ácido sulfúrico por 5 minutos, provavelmente causaram danos ao embrião, indicando que elas não suportam o aquecimento à temperatura de $80^{\circ} \mathrm{C}$ e o tempo que permaneceram no ácido sulfúrico foi excessivo, pois PEREZ (2004) relatou que, quando as sementes são expostas a altas temperaturas ou imersão em ácido sulfúrico por períodos prolongados, pode causar danos ao embrião, o que resulta em perda do vigor e viabilidade

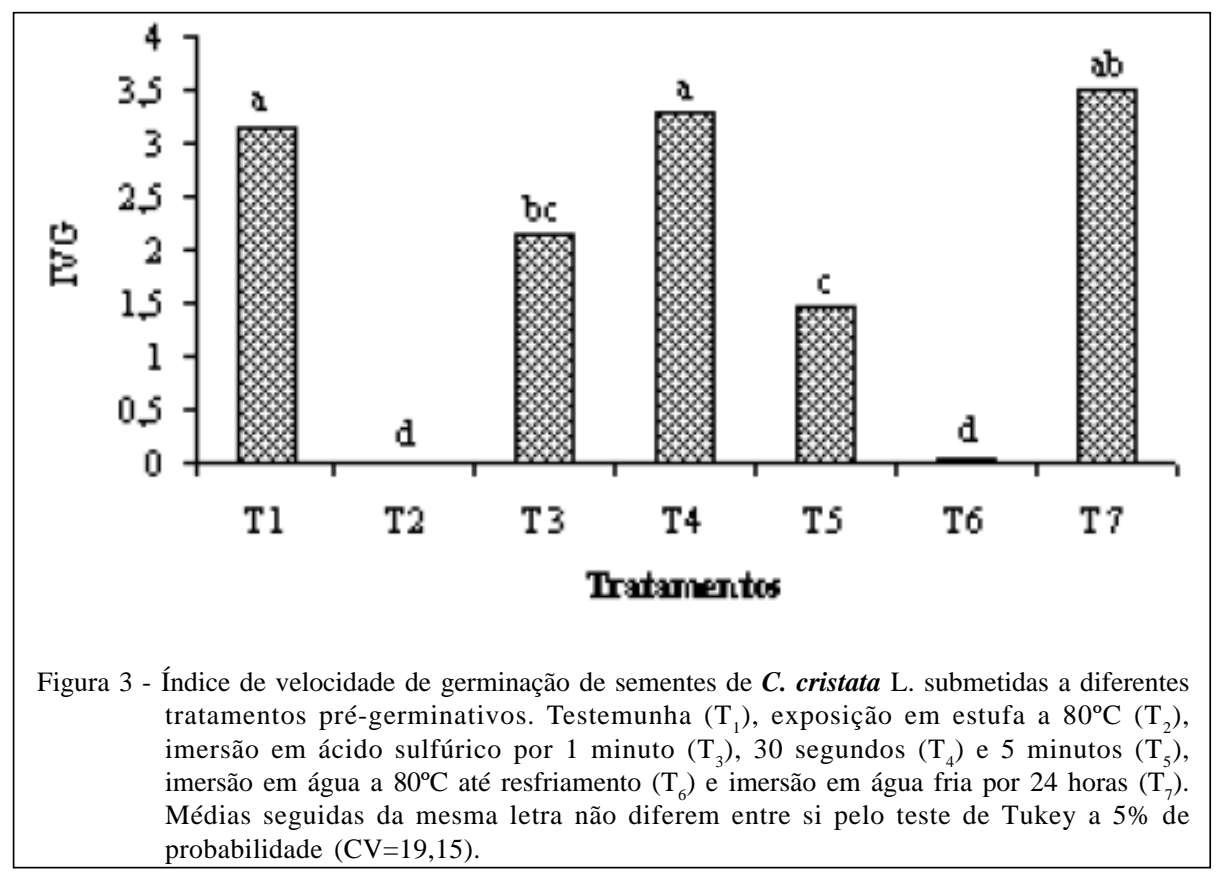

Ciência Rural, v.42, n.5, mai, 2012. 


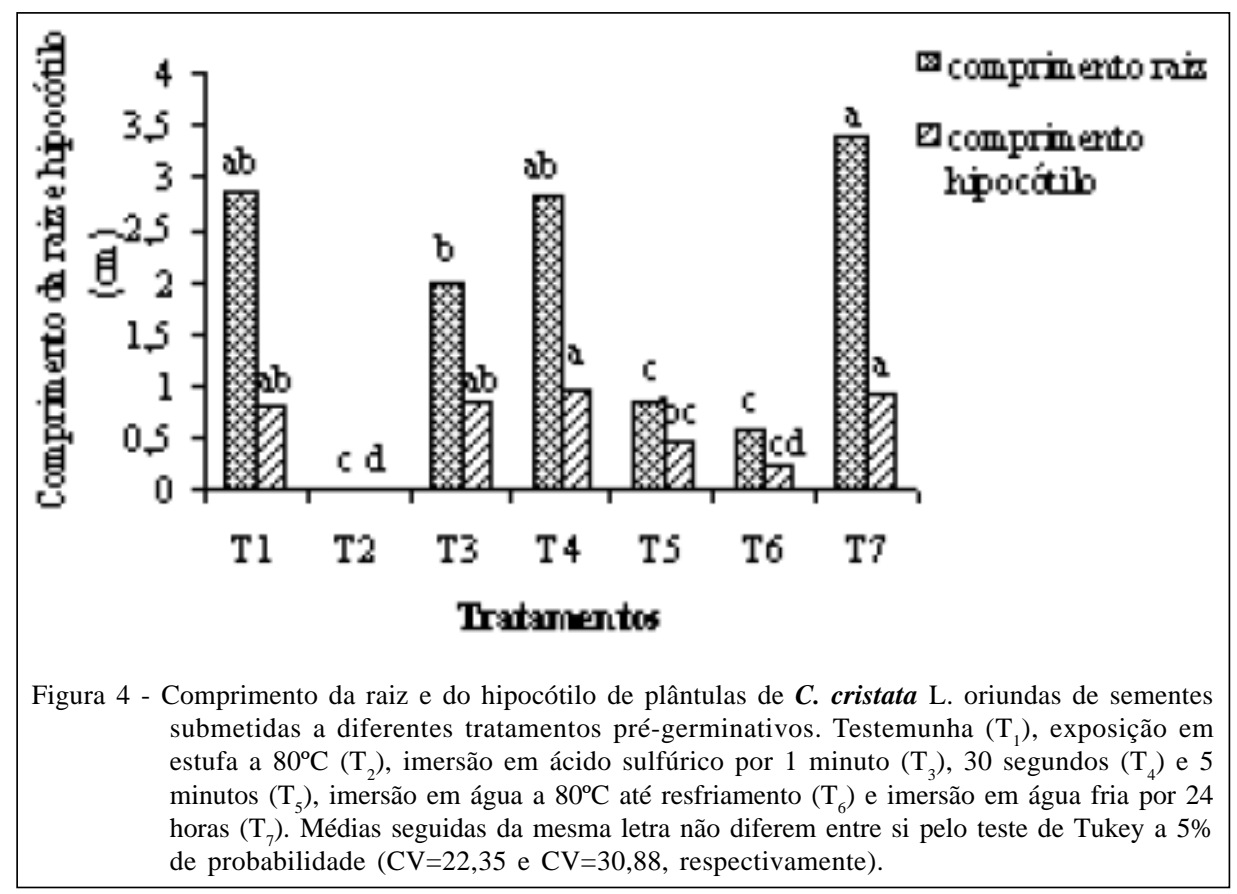

das sementes. Portanto, esses tratamentos não são indicados para as sementes desta espécie, uma vez que, segundo MARCOS FILHO (2005), o tratamento pré-germinativo não deve prejudicar o desempenho das sementes e o desenvolvimento das plântulas.

\section{CONCLUSÃO}

As sementes de $\boldsymbol{C}$. cristata L., quando oriundas de frutos maduros, não necessitam da utilização de tratamentos para superação da dormência.

\section{REFERÊNCIAS}

ALENCAR, K.M.C. et al. Tratamento térmico para superação da dormência em sementes de Stylosanthes SW. (Fabaceae Papilionoideae). Revista Brasileira de Sementes, v.31, n.2, p.164-170, 2009. Disponível em: <http://www.scielo.br/ pdf/rbs/v31n2/v31n2a19.pdf $>$. Acesso em: 20 fev. 2011. doi: 10.1590/S0101-31222009000200019.

AZANIA, C.A.M. et al. Superação da dormência de sementes de corda-de-viola (Ipomoea quamoclit e I. hederifolia). Planta daninha, v.27, n.1, p.23-27, 2009. Disponível em: <http:// www.scielo.br/pdf/pd/v27n1/a04v27n1.pdf>. Acesso em: 12 set. 2011.

ALVES, A.F. et al. Superação de dormência de sementes de braúna (Schinopsis brasiliense Engl.). Revista Ciência Agronômica, v.38, n.1, p.74-77, 2007. Disponível em: <http:/ / www.ccarevista.ufc.br/site/artigos_lista.php ?sel=2007\&sel2=1\&sel3=38>. Acesso em: 20 fev. 2011.

BARBOSA, A.P. et al. Tecnologia alternativa para a quebra de dormência das sementes de pau-de-balsa (Ochroma lagopus
Sw., Bombacaceae). Acta Amazonica, v.34, n.1, p.107-110, 2004. Disponível em: <http://www.scielo.br/scielo.php?script =sciissuetoc\&pid=0044-596720040001\&lng=pt $<$ \&nrm=iso $>$. Acesso em: 25 mar. 2011. doi: 10.1590/S004459672004000100013

BENEDITO, C.P. et al. Superação da dormência de sementes de catanduva (Piptadenia moniliformis Benth.). Revista Ciência Agronômica, v.39, n.1, p.90-93, 2008. Disponível em: <http://www.ccarevista.ufc.br/site/artigos_lista.php ?sel=2008\&sel2=1\&sel3=39>. Acesso em: 25 mar. 2011.

BEWLEY, J.D. Seed germination and dormancy. Plant Cell, v.9, n.7, p.1055-1066, 1997. Disponível em: <http:// www.ncbi.nlm.nih.gov/pmc/articles/PMC156979/pdf/ 091055.pdf>. Acesso em: 25 jun. 2011.

BIONDI, D.; LEAL, L. Tratamentos pré-germinativos em sementes de Mimosa strobiliflora Burkart. Scientia Agraria, v.9, n.2, p.245-248, 2008. Disponível em: <http:// ojs.c3sl.ufpr.br/ojs2/index.php/agraria/article/view/11013/ 8204>. Acesso em: 20 mar. 2011.

DAVIDE, A.C.; SILVA, E.A.A. Sementes florestais. In: DAVIDE, A.C.; SILVA, E.A.A. Produção de sementes e mudas de espécies florestais. Lavras: UFLA, 2008. p.11-82.

DIAS, D.C.F.S. Dormência em sementes: mecanismos de sobrevivência das espécies. Seed News, v.9, n.4, p.24-28, 2005. Disponível em: <http://www.seednews.inf.br/portugues/ seed94/artigocapa94.shtml>. Acesso em: 28 jan. 2011.

GILMAN, E.F.; HOWE, T. Celosia cristata. Florida: University of Florida, Institute of Food and Agriculture Science, 1999. 3p.

JACOB JUNIOR, E.A. et al. Tratamentos para superação da dormência em sementes de cornichão anual. Revista Brasileira de Sementes, v.26, n.2, p.15-19, 2004. Disponível 
em: <http://www.scielo.br/pdf/rbs/v26n2/24484.pdf>. Acesso em: 20 mar. 2011. doi: 10.1590/S0101-31222004000200003.

LORENZI, H.; SOUZA, H.M. Plantas ornamentais no Brasil: arbustivas, herbáceas e trepadeiras. 4.ed. Nova Odessa: Instituto Plantarum, 2008. 1088p.

MAGUIRE, J.D. Speed of germination-aid in selection and evaluation for seedlings emergence and vigor. Crop Science, v.2, n.2, p.176-177, 1962.

MARCOS FILHO, J. Dormência de sementes. In: MARCOS FILHO, J. Fisiologia de sementes de plantas cultivadas. Piracicaba: FEALQ, 2005. p.253-289.

MELO, R.R.; RODOLFO JÚNIOR, F. Superação de dormência em sementes e desenvolvimento inicial de canafístula (Cassia grandis L.F.). Revista Científica Eletrônica de Engenharia Florestal, ano IV, n.7, 15p. 2006. Disponível em: <http:// w w w . a r t i g o c i e n t if i c o . c o m . b r / u p lo a d s/ artc_1153973343_40.pdf>. Acesso em: 15 abr. 2011.

NASCIMENTO, I.L. et al. Superação da dormência em sementes de faveira (Parkia platycephala Benth.). Revista Árvore, v.33, n.1, p.35-45, 2009. Disponível em: <http://www.scielo.br/ pdf/rarv/v33n1/v33n1a05.pdf $>$. Acesso em: 18 abr. 2011. doi 10.1590/S0100-67622009000100005.
OKUSANYA, O.T. Germination and growth of Celocia cristata L. under various ligth and temperature regimes. American Journal of Botany, v.67, n.6, p.854-858, 1980.

PACHECO, M.V.; MATOS, V.P. Método para superação de dormência tegumentar em sementes de Apeiba tibourbou Aubl. Revista Brasileira de Ciências Agrárias, v.4, n.1, p.6266, 2009. Disponível em: <http://www.agraria.pro.br/sistema/ index.php?journal=agraria \&page $=$ article $\&$ op=view $\&$ path $\%$ 5B\%5D=10.5039\%2Frbca.2009.301\&path\%5B\%5D=272>. Acesso em: 20 mar. 2011. doi: 10.5039/agraria.v4i1a10.

PEREZ, S.C.J.G.A. Envoltórios. In: FERREIRA, A.G.; BORGHETTI, F. Germinação: do básico ao aplicado. Porto Alegre: Artmed, 2004. Cap.7, p.125-134.

RODRIGUES, A.P.D.C. et al. Tratamentos para superação da dormência de sementes de Adenanthera pavonina L. Revista Árvore, v.33, n.4, p.617-623, 2009. Disponível em: <http:// www.scielo.br/pdf/rarv/v33n4/v33n4a04.pdf>. Acesso em: 20 mar. 2011. doi: 10.1590/S0100-67622009000400004.

ZAIDAN, L.B.P.; BARBEDO, C.L. Quebra de dormência em sementes. In: FERREIRA, A.G.; BORGUETTI, F. Germinação: do básico ao aplicado. Porto Alegre: Artmed, 2004. Cap.8, p.135-146. 